\title{
The dilemmas of bilingual education in rural Ghana: A case study of the Nkwanta North District ${ }^{1}$
}

\author{
Abraham Kwesi Bisilki \\ Lecturer \\ Department of Applied Linguistics \\ University of Education, Winneba, Ghana \\ $\mathrm{PhD}$ Candidate \\ Department of Linguistics \\ The University of Hong Kong, Hong Kong \\ E-mail: bisilki@hku.hk; bisilki@yahoo.com
}

Submitted: January 31, 2018 / Accepted: October 20, 2018 / Published: December 3, 2018

\begin{abstract}
This paper relates to the broader purview of educational language policy in an African setting. It makes a contribution to the policy research and dialogue component of a National Literacy Acceleration Programme (NALAP), which is currently the school language policy strategy in Ghana. Through the use of structured questionnaires and a statistical analysis, the study assesses how the NALAP is being implemented in a scarcely referenced rural Nkwanta North District. A conclusion is reached that the NALAP is reduced to a mere ideological notion rather than an effectively run language policy in the Nkwanta North. The study also contends that any hope of the NALAP succeeding with its educational agenda in the Nkwanta North requires critical reforms in the local implementation framework, with some support from relevant central bodies.
\end{abstract}

Keywords: bilingual education, NALAP, medium of instruction, Twi, Likpakpaln 'Konkomba'

\footnotetext{
${ }^{1}$ My sincere appreciation goes to the three anonymous reviewers for their invaluable guidance in bringing this paper to the required standard. May I also acknowledge the assistance of Gideon Bisilki, a student at the Ghana School of Law, and Kwasi Enoch Ulorb in the process of writing this paper. Nevertheless, I remain solely responsible for any lapses, should there be any.
} 


\section{Introduction}

To find an all-embracing definition for bilingual education is as complicated as defining bilingualism itself (Močinić, 2011, p. 175). However, from a pedagogical perspective, bilingual education refers to a situation where education is provided in two languages, usually with the two languages serving as media of instruction (Močinić, 2011, p. 176). From the preceding point of view, I assume the position that a country can be said to have a bilingual language policy of education when there is a legimitisation of two languages as media of instruction in the formal school system. The sense of two languages can be considered from any of a number of possible combinations: native versus non-native, majority versus minority or two majority languages used in the school system.

Bilingual education, again, delineates into several submodels, including types as the early exit transitional and the late exit transitional forms. The former case is the trajectory of Ghana's current bilingual education that was rolled out under a new National Literacy Acceleration Programme (NALAP) that came into force in September, 2009 through the partnership of the Ministry of Education (MoE), Ghana, Ghana Education Service (GES) and the United States Agency for International Development (USAID). In an early exit transitional bilingual education, learners receive instruction in their L1 and in another language, usually up to two years of the early grades of school, after which the L1 is dropped as a medium of instruction (Baker, 2001; Močinić, 2011, p. 178). In the late exit system, however, around $40 \%$ of classroom instruction is allowed in the child's mother tongue until the $6^{\text {th }}$ grade of school (Močinić, 2011, p. 178). Under the NALAP dispensation in Ghana, learners in the early grades of school (kindergarten 1 [KG1] to Primary 3 [P3]) have the opportunity to receive instruction, literacy and numeracy skills in indigenous Ghanaian languages and the English language (see Leherr, 2009, p. i; Hartwell, 2010, p. iv). However, from primary 4 (P4) upwards, English alone becomes the medium of instruction, but a learner still has the opportunity to take a Ghanaian language as a subject of study (Dako \& Quarcoo, 2017, 
pp. 21-22).

The NALAP, as an educational language policy instrument, aimed at improving literacy rates in Ghana, has a tri-thematic focus stated as follows: That all children, from KG1 to P3 have access to quality literacy materials, effective instruction and public support to learn to read and write in their mother-tongue and English. A baseline assessment (Leherr, 2009) heralding the commencement of the NALAP confirmed comparatively high levels of real time as well as anticipated convulsions in the provision of language education in rural communities generally and in disadvantaged regions, such as the Northern and Upper Regions of Ghana. No wonder, similar challenges were again soon confirmed, following a NALAP implementation study by Hartwell (2010, pp. 44-45). As pointed out by Hartwell, there were hindrances related to the exclusion of native linguistic repertoires of a majority of pupils and teachers from the 11 NALAP approved Ghanaian languages, large numbers of untrained and transient teachers, late and uneven delivery of NALAP Teacher Guides and other NALAP instructional materials, etc. Although these problems are common to Ghana, they were projected as particularly more intense in the rural and in the northern sectors of the country. For instance, in the Sissala East District of the Upper West Region, neither teachers nor pupils could speak any of the 11 NALAP approved Ghanaian languages. Also, it is recorded (Hartwell, 2010, p. 44) that at the time of the implementation study, as many as $64 \%$ of the teachers present in the schools that were part of the implementation survey in the Northern Region were untrained/'pupil' teachers. It is, however, important to state clearly that the NALAP baseline assessment and the implementation study were not intended to be doomsayers. Rather, these were essentially to provide early warning signs and suggest precautionary mechanisms that would make the NALAP as successful as possible in meeting its functional targets. Indeed, both the baseline assessment and the implementation study proffered a comprehensive list of recommendations touching on all observed issues as well as anticipated challenges in the implementation of the NALAP. These recommendations, if followed, would help to 
ensure that the NALAP maximally realises its educational and literacy objectives.

The present study broadly investigates the issues of instructional effectiveness, instructional materials and the social marketing/public support dimensions of the NALAP in the Nkwanta North District in (Northern) Volta Region. In addition, attention is given to the extent to which the sociolinguistic phenomenon of language variation (barriers posed by the linguistic differences between the approved language of the school, the teachers' linguistic proficiencies and the language of the pupils or the community) affect the implementation of the NALAP in a scarcely researched community context like the Nkwanta North District. I used two sets of questionnaires (one for teachers of the lower grade classes$\mathrm{KG} 1$ to $\mathrm{P} 3$ and another for headteachers). The questionnaires comprised the Likert scale, the purely close-ended (yes/no) as well as open-ended response item types. Following a statistical analysis of responses, I argue that the NALAP, in its current state of implementation, remains only a plan rather than a practically implemented instrument in the context of a rural Nkwanta North District. Any expectation(s) or hope of rising above this challenge in the Nkwanta North requires very significant reforms in the local implementation framework, with some support from relevant central bodies. Questionnaires for the study are attached in separate files as appendixes I and II.

\section{The problem}

The central role of language in the provision and delivery of quality, functional education cannot be over-emphasised. However, language can only be a true asset for the education in a country if there is the right or suitable school language policy, backed by requisite resources and desirable implementation practices. It has been formally observed that Ghana's language policy of education has had a checkered history (Owu-Ewie, 2006, p. 76). It is also true to say, on a general note, that the task of couching and implementing language policies has proved frighteningly thorny for many countries in Africa and beyond (Azasu, 2012; 

Bamgbose, 2000; Das, 2002). It has, thus, been observed that even though most countries in Africa, including Ghana, have churned out educational language policies that stress the use of the child's L1 (a native language) as medium of instruction (MOI), little effort has been made in practically ensuring that such policies are well implemented (Mose, 2017, p. 217; Owu-Ewie, 2017, p. 152).

Tanzania has been cited as probably the only example of an African polity where the policy of education in mother tongue has been successfully implemented. In Tanzania, Kiswahili is well used as a MOI throughout the primary school level (Mose, 2017, p. 216).

Indeed, the challenges and wrangling in managing Ghana's educational language policy are partly reflected in the unstable switches between emphasised and de-emphasised Ghanaian language MOI regimes in the policy models. These changes, from the year 2000 till present can be represented as shown in the table below:

Table 1: A representation of the changes in Ghana's school language policy (from the year 2000 to present) ${ }^{1}$

\begin{tabular}{|l|l|l|l|l|}
\hline Period & Year 1 & Year 2 & Year 3 & $\begin{array}{l}\text { Year 4 } \\
\text { onwards }\end{array}$ \\
\hline $2000-2002$ & + & + & + & - \\
\hline $2002-2007$ & - & - & - & - \\
\hline $2007-2009$ & + & + & + & - \\
\hline $\begin{array}{l}\text { September, 2009 } \\
\text {-present }\end{array}$ & + & + & + & - \\
\hline
\end{tabular}

Key to table 1: $(+)=$ the inclusion of Ghanaian language as medium of instruction in the early years of school

$(-)=$ the exclusion of Ghanaian language as medium of instruction in the early years of school.

Table 1 represents the early years of school beginning from primary 1 . This is because until more recently, many basic schools, especially in the interior and rural communities of Ghana did not

1 Table 1 is with a cue from Ansah and Agyeman (2015, p. 92), also after Owu-Ewie (2006). 
have kindergarten units. This situation has not changed completely as there are still a few cases of basic schools without KGs, meaning some children start school in primary 1 . An instance that typifies this is that of the Nkwanta North. A look at the 2017/2018 Annual District Performance Report of GES, Nkwanta North reveals that whereas there are 63 public primary schools in the district, the corresponding number of KGs in the public primary schools is 57 . Probably, this phenomenon further resonates with the currently prevailing reality whereby government owned or public basic schools in Ghana do not mandatorily have the nursery levels (Ansah \& Agyeman, 2015, p. 90).

The present language-in-education approach, the NALAP, was started in September, 2009. Related investigations and assessments preceding the start of the NALAP consistently revealed that Ghana had been neck-deep in a national literacy and numeracy crisis. In more concrete terms, it was shown, for instance, that only $26 \%$ of pupils reaching primary 6 (P6) became literate in the English language whilst only a further lower $11 \%$ became numerate by P6 (Leherr, 2009). Improving Education Quality (2000, p. 1) also earlier attested to the low literacy level that bedeviled Ghanaian pupils and students. One can conclude, based on these gloomy accounts, that Ghana's school language policy epochs succeeded by the NALAP left much to be desired, if weighed in the light of the very reasons for their formulation and implementation.

With a full consciousness of the challenges that beset the successful implementation of previous school language policies in Ghana, the NALAP was planned and programmed to be implemented in a way that should make it a successful language programme. For instance, the NALAP is particularly fashioned to be unique as it purportedly gives a learner the opportunity for the use and development of literacy skills in English (a foreign, but Ghana's official language) and a Ghanaian language concurrently: 
In NALAP, pupils learn how to read and write in a Ghanaian language, with English introduced gradually, and initially orally only. By P2, pupils also start to read and write in English, and by P3 pupils should be able to read with fluency and understanding in both a Ghanaian language and English. (Hartwell, 2010, p. iv).

This educational language policy strategy, more importantly, has the often desirable recourse to compelling research findings cross-globally that mother tongues are the ideal vehicles for knowledge delivery, particularly during early child education (Cummins, 2000; Maalim, 2015; UNESCO, 1953). It must also be acknowledged that this mode of bilingual education espoused under the NALAP, to some extent, takes due cognisance of the learner's Linguistic Human Right (LHR) as has been enshrined in a United Nations' 1992 charter (Owu-Ewie, 2017; SkutnabbKangas \& Phillipson, 1994; UNHCR, 2010). Consistent with the United Nations' declaration on LHR, all persons, irrespective of which group they belong to, should have the opportunity to learn in their mother-tongue or have instruction in their mother-tongue (UNHCR, 2010, p. 27).

Somehow, several years down the line, the NALAP appears not to be developing for itself a story different from that of earlier school language policy regimes implemented in Ghana. As hinted by Dako and Quarcoo (2017, pp. 24-25), the elite schools (mostly private) that resort to English only as MOI have advantage over the public schools that comply with the official educational language policy (the NALAP). Informal interactions with some stakeholders about the state of the NALAP in the Nkwanta North District suggest that the NALAP has not lived up to expectation with regard to its implementation. This study is meant to evaluate the state of implementation of the educational language policy in the Nkwanta North, with the view to bringing to light whether or not the policy is being successful in this area. By so doing, the study also contributes to the policy research and dialogue component of the NALAP. An equally important motivation for this study is that 
although a number of scholarly works (e.g., Andoh-Kumi, 1997; Anyidoho \& Anyidoho, 2009; Ansah, 2014; Awedoba, 2009) have, over the years, been undertaken into aspects of Ghana's language policy in education, it seems that none of these directly focuses on the Nkwanta North or on any of the areas contiguous to it. The following sections will deal with the sociolinguistic situation in the Nkwanta North, the educational profile of the Nkwanta North, research methodology, respondent demographics, presentation of data and analysis, summary of findings, implications and, then, the conclusion of the study.

\section{The sociolinguistic situation in the Nkwanta North District}

The Nkwanta North District is located between $7^{\circ} 30^{\prime} \mathrm{N}$ and $8^{\circ} 45^{\prime} \mathrm{N}$ and $0^{\circ} 10^{\prime} \mathrm{W}$ and $0^{\circ} 45^{\prime} \mathrm{E}$. The district was carved out of the then Nkwanta District (now Nkwanta South) and commissioned on the $29^{\text {th }}$ of February, 2008 under the establishment of Legislative Instrument (LI) 1846 of 2008. It is one of the 25 districts in the Volta Region and has Kpassa as its district capital (Nkwanta North District Assembly [NNDA], 2015). The Nkwanta North has an estimated total population of 64,553, of which the male and female populations stand at 32,394 and 32,159, respectively (Ghana Statistical Service [GSS], 2012, p. 6). The district has 85 communities and $78 \%$ of the people dwell in rural areas. Agriculture engages about $80 \%$ of the labour force and there is no single tarred road in the district (NNDA, 2015, p. 4). Interestingly, the Nkwanta North is the northernmost district in the northern part of the Volta Region that is also sometimes referred to as 'Northern Volta'. Damanko, which is both administratively and geographically a border community between the Northern Region and the Volta Region is located in the Nkwanta North District.

Linguistically, the Nkwanta North District is a highly multilingual area. The list of Ghanaian indigenous languages spoken in the district is certainly long and the exact number of such languages is indeterminate for now. However, one can mention the following Ghanaian languages: Likpakpaln (Konkomba), Bassari, Kotokoli, Chakosi (a variety of Anufo), Ewe, Nawuri, Challa and 
Kabre as some of those languages used in the District. A variety of Twi is also evident in the Nkwanta North as it, to some extent, serves as a lingua franca for the area. However, this Twi remains only as a second language the people get to speak later after acquiring their respective L1s. Although Likpakpaln is clearly the major native language of the Nkwanta North (see Bisilki, 2017, p. 36), not many people from the other ethnic groups or language groups learn to speak it fluently, except that a majority of them still attain some minimal level of comprehension of Likpakpaln and the ability to say a few words in it. Nonetheless, it is worthwhile to note that even those who speak Likpakpaln fluently as a second language still keep to their own mother tongue in interactions with their children and families at home. The present observation is not far from that of the GSS (2014, p. 4) when it indicates that the ethnic groups in the Nkwanta North include the Konkombas, Bassaris, Ewes, Akans and others hailing from the Northern Region, but that the dominant group is the Konkomba, followed by Bassari.

The use of the English language in communication is very much circumscribed in the Nkwanta North District. In offices and other formal work places, people prefer to use Twi or another Ghanaian language as may be suitable for the interactants. This is especially the case when officers or staff are attending to members of the public (most of whom cannot speak the English language). The only context where the English language is more regularly used is the school setting, although this is also not totally without codeswitches to other native languages as may be possible between the interactants.

\section{The educational profile of the Nkwanta North District}

The Nkwanta North District has a total of 74 educational institutions. These include 2 second cycle institutions (1 senior high/ technical school and 1 technical/vocational institute) and 72 basic schools. The district is divided into 7 educational administrative circuits (GES, Nkwanta North, 2017). As of June, 2014, the number of trained teachers stood at 165 as against 214 untrained teachers. Similarly, only $47 \%$ of the junior high school (JHS) pupils obtained 
qualifying aggregates for entry into the senior high school (SHS), (NNDA, 2015, p. 5). The literacy rate in the district is very low. $69.4 \%$ of persons 11 years and older in the district are non-literate and $62.6 \%$ of persons 3 years and older in the district have never attended school (GSS, 2014, pp. 36-8). There are also general educational infrastructural shortfalls, with many of the schools lacking important facilities such as a school library.

\section{Research methodology}

This study is basically a descriptive survey. A descriptive research may describe a natural or a man-made educational phenomenon that is of interest to educators and policy makers. A descriptive study can generate rich data that provide the basis for important recommendation as exemplified in Galloway (1992).

I used two sets of written questionnaire (one for lower primary school class teachers and the other for headteachers). These questionnaires were administered in-person by me (with the assistance of one voluntary field assistant) in the Nkwanta North District. The data collection was carried out in October, 2017. The face-to-face mode of questionnaire administration made it possible to verify respondents' self-characterisation and to also ask or answer clarification questions where necessary (see Schilling, 2013, p. 99 for the advantages of face-to-face administration of surveys). A majority of the question items in these questionnaires were modelled after a USAID [GH] School Language Mapping Project that was carried out in February-April, 2017 across parts of all the 10 regions of Ghana, which did not include the Nkwanta North District. Before analysing the administered questionnaires, the questions and responses were first coded and entered onto two separate grids (one for the class teacher questionnaire and the other for the headteacher questionnaire). The data collated onto the simple grids were further analysed into descriptive statistics, mainly of frequencies and percentages.

The study involved a total of 98 respondents (81 lower primary school teachers and 17 headteachers) drawn from 16 randomly selected basic schools. Once a school was selected, its 
headteacher and the lower grade class teachers became automatic respondents, although each respondent still participated only voluntarily.

\section{Respondent demographics}

Tables 2 and 3 below show the age and gender distribution of the headteacher and the class teacher respondents respectively. Table 4, on its part, shows teacher and class level distribution.

Table 2: Age and gender distribution of headteacher respondents

\begin{tabular}{|l|l|l|l|}
\hline \multirow{2}{*}{$\begin{array}{l}\text { Age distribution } \\
\text { (years) }\end{array}$} & \multirow{2}{*}{ No. of respondents } & \multicolumn{2}{|c|}{ Gender } \\
\cline { 3 - 4 } & & Male & Female \\
\hline $16-20$ & $1(5.9 \%)$ & $1(5.9 \%)$ & $0(0 \%)$ \\
\hline $21-30$ & $2(11.8 \%)$ & $2(11.8 \%)$ & $0(0 \%)$ \\
\hline $31-40$ & $12(70.6 \%)$ & $9(52.9 \%)$ & $3(17.6 \%)$ \\
\hline $41-50$ & $2(11.8 \%)$ & $2(11.8 \%)$ & $0(0 \%)$ \\
\hline $51-60$ & $0(0 \%)$ & $0(0 \%)$ & $0(0 \%)$ \\
\hline Above 60 & $0(0 \%)$ & $0(0 \%)$ & $0(0 \%)$ \\
\hline Total & $17(100.1 \%)$ & $14(82.4 \%)$ & $3(17.6 \%)$ \\
\hline
\end{tabular}

From the results in Table 2, it can be noted that a total of 17 headteachers participated in this survey. Out of the 17 headteachers, $14(82.4 \%)$ were males while only $3(17.6 \%)$ were females. Also, a majority $(12(70.6 \%))$ of the headteachers were found to be within the age range of 31-40. 
Table 3: Age and gender distribution of class teacher respondents

\begin{tabular}{|l|l|l|l|}
\hline \multirow{2}{*}{$\begin{array}{l}\text { Age distribution } \\
\text { (years) }\end{array}$} & \multirow{2}{*}{$\begin{array}{l}\text { No. of } \\
\text { respondents }\end{array}$} & \multicolumn{2}{|c|}{ Gender } \\
\cline { 3 - 4 } & $2(2.5 \%)$ & $2(2.5 \%)$ & $0(0 \%)$ \\
\hline $16-20$ & $43(53.1 \%)$ & $13(16.0)$ & $30(37.0)$ \\
\cline { 2 - 4 } & $2(2.5 \%)$ & $0(0 \%)$ & $0(0 \%)$ \\
\hline $31-40$ & $23(28.4 \%)$ & $11(13.6)$ & $12(14.8 \%)$ \\
\hline $41-50$ & $5(6.2 \%)$ & $1(1.2)$ & $4(4.9)$ \\
\hline $51-60$ & $1(1.2 \%)$ & $0(0 \%)$ & $1(1.2)$ \\
\hline Above 60 & $0(0 \%)$ & $0(0 \%)$ & $0(0 \%)$ \\
\hline No age indicated & $5(6.2 \%)$ & $1(1.2)$ & $4(4.9)$ \\
\hline Total & $81(100 \%)$ & $28(34.5 \%)$ & $51(62.8 \%)$ \\
\hline
\end{tabular}

As can be seen from Table 3, 81 lower primary class teachers served as respondents to the questionnaire. A majority (being 43 $(53.1 \%)$ of the lower primary school teacher respondents fell within the age range of 21-30. $28(34.5 \%)$ and $51(62.8 \%)$ out of the 81 respondents were males and females respectively. Nevertheless, it is worthy of note that two of the class teacher respondents (in the age range 21-30) did not indicate their gender in answering the questionnaire. It is, however, intriguing to observe that although the female class teacher population far outweighs that of the male (as can be seen in Table 3), the majority of school heads were found to be males as can be noted in Table 2. On the other hand, the imbalance between male and female class teacher populations at the lower primary could inure to the benefit of the NALAP in the Nkwanta North. This is because of the observation that female teachers are better at teaching reading than their male counterparts (Leherr, 2009, p. 35). 
Bisilki, A. K./ The dilemmas of bilingual education in rural Ghana

Table 4: Teacher respondent and classes taught

\begin{tabular}{|l|l|l|l|l|l|}
\hline $\begin{array}{c}\text { Gender of } \\
\text { teacher }\end{array}$ & \multicolumn{5}{|c|}{$\begin{array}{c}\text { Distribution of teachers and class } \\
\text { levels taught }\end{array}$} \\
\hline & KG 1 & KG 2 & P 1 & P 2 & P 3 \\
\hline Male & 2 & 3 & 3 & 6 & 14 \\
\hline Female & 11 & 11 & 10 & 11 & 8 \\
\hline $\begin{array}{l}\text { No gender } \\
\text { indicated }\end{array}$ & 1 & 0 & 1 & 0 & 0 \\
\hline $\begin{array}{l}\text { Totals per class } \\
\text { level }\end{array}$ & 14 & 14 & 14 & 17 & 22 \\
\hline
\end{tabular}

From table 4, it can be observed that out of the 81 class teachers, there were $14 \mathrm{KG} 1$ teachers, $14 \mathrm{KG} 2$ teachers, $14 \mathrm{P} 1$ teachers, $17 \mathrm{P} 2$ teachers and $22 \mathrm{P} 3$ teachers. Two of the teachers (i.e., $1 \mathrm{KG} 1$ teacher and $1 \mathrm{P} 1$ teacher) did not indicate their gender on the questionnaire. This is earlier pointed out in table 3.

\section{Presentation of data and analysis}

In this presentation of results, questions that were asked in the questionnaire are organised into thematic areas. These are then analysed by providing the response options and the corresponding distribution of responses by the class teachers and the headteachers as in the following tables: 
Table 5: Frequency distributions on the dominant language spoken in the communities where respondents' schools are located.

\begin{tabular}{|l|l|l|}
\hline \multirow{2}{*}{$\begin{array}{l}\text { Languages mentioned } \\
\text { by respondents as } \\
\text { dominant in the } \\
\text { communities }\end{array}$} & \multicolumn{2}{|c|}{ Distribution of responses } \\
\cline { 2 - 3 } & $\begin{array}{l}\text { Class teachers: } \\
\text { Frequency }\end{array}$ & $\begin{array}{l}\text { Headteachers: } \\
\text { Frequency }\end{array}$ \\
\hline Likpakpaln (Konkomba) & $76(93.83 \%)$ & $15(88.24 \%)$ \\
\hline Twi & $4(4.94 \%)$ & $2(11.76 \%)$ \\
\hline Kotokoli & $1(1.23 \%)$ & $0(0 \%)$ \\
\hline Total & $81(100 \%)$ & $17(100 \%)$ \\
\hline
\end{tabular}

Table 5 shows that the languages that were identified by respondents as dominant in their school environs included Likpakpaln, Twi and Kotokoli. 76 (93.83\%) of the class teachers mentioned Likpakpaln as the language predominantly used in the local communities where their schools are located as 4 (4.94\%) and $1(1.23 \%)$ identified Twi and Kotokoli, respectively as the dominant languages of the communities where their schools are located. On the part of the head teachers, $15(88.24 \%), 2(11.76 \%)$ and 0 $(0 \%)$ indicated that Likpakpaln, Twi and Kotokoli, respectively are dominant in the communities of their schools. From the above results, it is clear that a majority of the lower primary school teachers and the headteachers recognise Likpakpaln as the majority language in the environments where their schools are situated. From the data gathered, Twi is the next in that regard and Kotokoli ranks least. This finding matches with the report of GSS (2014, p. 4) that Konkomba is the dominant ethno-linguistic group in the Nkwanta North. 
Table 6: Frequency distributions on the Ghanaian language spoken as L1 by the majority of pupils in lower primary classes

\begin{tabular}{|c|c|c|}
\hline \multirow{2}{*}{$\begin{array}{l}\text { The Ghanaian languages } \\
\text { identified by respondents } \\
\text { as spoken by the } \\
\text { majority of pupils in the } \\
\text { lower primary grades }\end{array}$} & \multicolumn{2}{|c|}{ Distribution of responses } \\
\hline & $\begin{array}{l}\text { Class teachers: } \\
\text { Frequency }\end{array}$ & $\begin{array}{l}\text { Headteachers: } \\
\text { Frequency }\end{array}$ \\
\hline Likpakpaln & $74(91.36 \%)$ & $13(76.47 \%)$ \\
\hline Twi & $3(3.70 \%)$ & $3(17.65 \%)$ \\
\hline Kotokoli & $4(4.94 \%)$ & $1(5.88 \%)$ \\
\hline Total & $81(100 \%)$ & $17(100 \%)$ \\
\hline
\end{tabular}

Based on the results presented in Table 6 above, it is evident that a greater number of the class teachers (74[91.36\%]) and headteachers $(13[76.47 \%])$ are of the view that the Ghanaian language spoken by a majority of the lower grade primary pupils is Likpakpaln. We also discover from the results that $3(3.70 \%)$ of the class teachers consider Twi to be the Ghanaian language spoken by most of their pupils in the lower grades of primary school. 4 (4.94) of these class teachers also hold the view that Kotokoli is the majority language among their pupils in lower primary. On the part of the headteachers, $3(17.65 \%)$ hold that Twi is the Ghanaian language used by a majority of their lower grade pupils whilst 1 $(5.88 \%)$ of these headteachers also state that Kotokoli remain the dominant language for a majority of the pupils concerned.

However, an intriguing development on this question lies with the contrast in opinion between the class teachers and the headteachers regarding Twi and Kotokoli. The number of class teachers (4[4.94\%]) who mention Kotokoli as dominant among the pupils is slightly higher than those $(3[3.70 \%)$ who say so for Twi. In contrast, the number of headteachers (3[17.65\%]) who declare Twi as the more dominant variety among pupils in lower primary is higher than those (1[5.88\%]) who say so for Kotokoli. Nonetheless, the critical point here is that whilst Likpakpaln is the 
L1 of a majority of the pupils, it is Twi that is used as the Ghanaian language MOI in their classrooms. The consequence, then, is that this majority of pupils are deprived of the great advantages that come with receiving education/knowledge in one's own mother tongue.

Table 7: The NALAP approved Ghanaian language of instruction/ teaching at the lower primary level in the Nkwanta North District

\begin{tabular}{|l|l|l|}
\hline \multirow{2}{*}{$\begin{array}{l}\text { The GES approved } \\
\text { Ghanaian language for } \\
\text { instruction/teaching at the } \\
\text { lower primary in Nkwanta } \\
\text { North }\end{array}$} & \begin{tabular}{l} 
Distribution of responses \\
\cline { 2 - 3 }
\end{tabular} & Frequency \\
\hline Likpakpaln & $\begin{array}{l}\text { Headteachers: } \\
\text { Frequency }\end{array}$ \\
\hline Twi & $66(8.64 \%)$ & $0(0 \%)$ \\
\hline Likpakpaln and Twi & $4(4.94 \%)$ & $16(94.12)$ \\
\hline No response & $4(4.94 \%)$ & $0(0 \%)$ \\
\hline Total & $81(100 \%)$ & $17(100 \%)$ \\
\hline
\end{tabular}

The responses of both the class teachers (66[81.48\%]) and the headteachers $(16[94.12 \%])$ give a strong confirmation that Twi is the NALAP approved Ghanaian language of instruction and teaching at the lower primary level in the Nkwanta North District. This was further corroborated by my own verification with the Nkwanta North District Directorate of the GES.

Nonetheless, other Ghanaian languages were mentioned by some respondents as the approved media of instruction for the educational level concerned in the district. As the statistics in table 7 show, 7 class teachers, representing 8.64\% mentioned Likpakpaln as the approved Ghanaian language of instruction in the district and $4(4.94 \%)$ said that both Likpakpaln and Twi are approved, under the NALAP, for instruction and teaching in the grades concerned. In the case of the headteachers, only $1(5.88 \%)$ gave the option that both Likpakpaln and Twi were GES approved Ghanaian languages for instruction and teaching at the lower primary level in 
the Nkwanta North. The incidence of some respondents mentioning other languages other than Twi as the NALAP approved language(s) of instruction, most likely, betrays their unfamiliarity with the tenets of the NALAP. This becomes especially remarkable when one considers the fact that the question posed was very straightforward in asking the respondents to indicate the 'NALAP approved' language of instruction and not just any other language(s) that teachers may tend to use in the classroom in the Nkwanta North. Class teachers and headteachers are key stakeholders in the execution of a school language programme such as the NALAP. As such, their being poorly informed on the basic provisions of the policy is nothing, but the misinterpretation and improper implementation as was the case in Kenya (Mose, 2017).

Table 8: Frequency distributions on which Ghanaian language will best serve as the medium of instruction and teaching at the lower primary level in the Nkwanta North

\begin{tabular}{|l|l|l|}
\hline \multirow{2}{*}{$\begin{array}{l}\text { The most suitable } \\
\text { Ghanaian language } \\
\text { option to be adopted for } \\
\text { instruction/teaching at } \\
\text { the lower primary in } \\
\text { Nkwanta North }\end{array}$} & $\begin{array}{l}\text { Class teachers: } \\
\text { Frequency }\end{array}$ & $\begin{array}{l}\text { Headteachers : } \\
\text { Frequency }\end{array}$ \\
\cline { 2 - 3 } Likpakpaln & $60(74.07 \%)$ & $14(82.85 \%)$ \\
\hline Twi & $14(17.28 \%)$ & $1(5.88 \%)$ \\
\hline Likpakpaln and Twi & $4(4.94 \%)$ & $1(5.88 \%)$ \\
\hline Kotokoli & $1(1.23 \%)$ & $1(5.88 \%)$ \\
\hline No response & $2(2.47 \%)$ & $0(0 \%)$ \\
\hline Total & $81(100 \%)$ & $17(100 \%)$ \\
\hline
\end{tabular}

As can be seen from Table 8, $60(74.07 \%)$ of the class teachers share the view that Likpakpaln will be the most appropriate Ghanaian language to serve as the medium of instruction and learning at the lower primary level in the Nkwanta North District. 
Apart from the preceding response foregrounding Likpakpaln as the L1 of majority of the school children and their teachers, it also serves as evidence of strong support by stakeholders for mother tongue-based bilingual education. $14(17.28 \%)$ of the class teachers also proposed that Twi will be the best Ghanaian language for instruction and learning at the lower grades of school in the Nkwanta North, meaning Twi should be maintained in use as currently being done. $4(4.94 \%)$ of these class teachers hold the view that adopting both Likpakpaln and Twi as media of instruction and teaching will be the best way to go. Similarly, $1(1.23 \%)$ of the class teachers are of the view that Kotokoli will be the best language for education at the lower grades of school in the Nkwanta North. Nevertheless, 2 $(2.47 \%)$ of the class teachers did not indicate at all which Ghanaian language they think will be most beneficial if adopted for education at the lower grades in the Nkwanta North District.

Turning to the views of the headteachers on this issue, 14 $(82.85 \%)$ of them state that Likpakpaln will be the best Ghanaian language for education at the lower grades in the Nkwanta North District. Also, the Ghanaian language options: Twi, both Likpakpaln and Twi and Kotokoli each has 1 (5.8\%) headteacher endorsing them as the best to be used for instruction and teaching at the lower primary school in the Nkwanta North. Furthermore, the fact that Twi is the NALAP chosen Ghanaian language MOI as against the stance of the class teachers and the headteachers that Likpakpaln would have been the best Ghanaian language MOI marks a disagreement between the NALAP and its implementers in the Nkwanta North. Differences in beliefs and ideologies can lead implementers to contravening and contesting a school language policy (Spolsky, 2009). 
Table 9: Frequency distributions on teacher mother-tongue

\begin{tabular}{|l|l|}
\hline $\begin{array}{l}\text { L1 of class teacher } \\
\text { respondents }\end{array}$ & $\begin{array}{l}\text { Distribution of } \\
\text { teachers (frequency) }\end{array}$ \\
\hline Twi & $13(16.04 \%)$ \\
\hline Likpakpaln & $37(45.68 \%)$ \\
\hline Bassari & $5(6.17 \%)$ \\
\hline Challa & $1(1.23 \%)$ \\
\hline Hausa & $4(4.94 \%)$ \\
\hline Ewe & $13(16.04 \%)$ \\
\hline Adele & $1(1.23 \%)$ \\
\hline Nawuri & $2(2.47 \%)$ \\
\hline Sissali & $1(1.23 \%)$ \\
\hline Chumburu & $1(1.23 \%)$ \\
\hline Krachi & $1(1.23 \%)$ \\
\hline Dangme & $1(1.23 \%)$ \\
\hline No response & $1(1.23 \%)$ \\
\hline Total & $81(100 \%)$ \\
\hline
\end{tabular}

The responses analysed in Table 9 were elicited to ascertain the L1 backgrounds of the lower primary school teachers. Here, each respondent class teacher was asked to mention which Ghanaian language was his or her mother tongue. It was found that the lower primary class teachers involved came from as varied as 12 different mother-tongues, namely, Twi, Likpakpaln, Bassari, Challa, Hausa, Ewe, Adele, Nawuri, Sissali, Chumburu, Krachi and Dangme. In an ascending order, the first five L1 groups with higher class teacher representations at the lower grades included: Hausa 4 (4.94\%), Bassari 5 (6.17\%), Ewe 13 (16.04\%) and Twi 13 (16.04\%) and Likpakpaln 37 (45.68\%). Coincidentally, the number of class teachers who spoke Twi as their L1 and those who have Ewe as their mother tongue stood at the same figure of $13(16.04 \%)$. 
Table 10: Frequency distribution on whether or not the class teachers have received in-service training on language/literacy teaching

\begin{tabular}{|l|l|}
\hline Response options & $\begin{array}{l}\text { Frequency distribution of } \\
\text { responses }\end{array}$ \\
\hline Yes & $31(38.27)$ \\
\hline No & $50(61.73 \%)$ \\
\hline Total & $81(100 \%)$ \\
\hline
\end{tabular}

As can be seen from the results in Table 10 above, 50 $(61.73 \%)$ of the class teacher respondents said that they had not attended any workshop or training on language/literacy teaching since they became teachers. 31 (38.27) of the class teachers, however, indicated that they had had the opportunity to attend training programmes on language/literacy teaching while in service. The finding under this theme suggests a severe indictment of the system. The implementation of any bilingual education policy is bound to be ineffective if teachers are not regularly re-trained in and updated on modern trends and methodologies.

Table 11: Frequency distribution on how many years ago since the class teachers attended any workshop/training related to language pedagogy while in teaching service

\begin{tabular}{|l|l|}
\hline Time frame & Frequency \\
\hline Less than 1 year & $0(0 \%)$ \\
\hline $1-2$ years & $5(16.03 \%)$ \\
\hline $3-4$ years & $13(41.94 \%)$ \\
\hline $5-6$ years & $0(0 \%)$ \\
\hline 7-8 years & $9(29.03 \%)$ \\
\hline Above 8 years & $3(9.68 \%)$ \\
\hline No response & $1(3.23 \%)$ \\
\hline Total & $31(100 \%)$ \\
\hline
\end{tabular}


A follow-up question was posed to the 31 class teachers who responded Yes to the question analysed in Table 10 to indicate how long it had been since they attended the last training/workshop on language/literacy teaching. The result is as presented in Table 11. A majority of $13(41.94 \%)$ of the teachers stated that they attended a training programme 3-4 years ago. 9 (29.03\%) of the teachers, which is next to the majority attended such a workshop/training since 7-8 years ago. The most recent time any of the class teachers benefitted from any such training was 1-2 years ago, but only 5 $(16.03 \%)$ of the class teachers had the opportunity to participate in a training programme within that period.

Table 12: Frequency distribution on whether or not the class teachers are aware of the NALAP in Ghana

\begin{tabular}{|l|l|}
\hline Response options & Frequency \\
\hline Yes & $62(76.54 \%)$ \\
\hline No & $17(20.99 \%)$ \\
\hline No response & $2(2.47 \%)$ \\
\hline Total & $81(100 \%)$ \\
\hline
\end{tabular}

From the data presented in Table 12, it can be seen that $62(76.54 \%)$ of the teachers affirmed that they were aware of the NALAP. On the contrary, 17 (20.99\%) said they did not know of the NALAP while $2(2.47 \%)$ did not indicate a Yes or No to the question.

Table 13: Frequency distribution on availability of NALAP policy document in schools

\begin{tabular}{|l|l|}
\hline Response options & Frequency \\
\hline Yes & $4(23.53 \%)$ \\
\hline No & $13(76.47 \%)$ \\
\hline Total & $17(100 \%)$ \\
\hline
\end{tabular}


The headteacher respondents were asked to indicate by a Yes or No to show if their respective schools had copies of the NALAP programme document. From their responses as shown in table 13 , only $4(23.53 \%)$ of the headteachers had copies of the NALAP document in their schools as against 13 (76.47\%) who said their schools had no copies of the document. This situation, obviously, means that opportunity for reference to the language policy documented is grossly limited, leading to a poorly informed educator phenomenon.

Table 14: Frequency distribution on availability of NALAP teaching learning materials (TLMs)

\begin{tabular}{|l|l|}
\hline Response options & Frequency \\
\hline Strongly agree & $0(0 \%)$ \\
\hline Agree & $2(11.76 \%)$ \\
\hline Disagree & $9(52.92)$ \\
\hline Strongly disagree & $6(35.29 \%)$ \\
\hline Total & $17(100 \%)$ \\
\hline
\end{tabular}

The headteachers were also asked to indicate their level of agreement with the statement that their respective schools had enough copies of the NALAP teacher guide and other NALAP TLMs. From the responses as represented in Table 14, a greater number of the headteachers (9[52.92\% and 6[35.29\%]) either disagreed or strongly disagreed with the afore-statement. Only 2 $(11.76 \%)$ of them were in agreement with the statement. 
Table 15: Frequency distributions on public awareness of the NALAP in the Nkwanta North

\begin{tabular}{|l|l|l|}
\hline \multirow{2}{*}{$\begin{array}{l}\text { Response } \\
\text { options }\end{array}$} & \multicolumn{2}{|l|}{ Distribution of responses } \\
\cline { 2 - 3 } & $\begin{array}{l}\text { Class teachers: } \\
\text { Frequency }\end{array}$ & $\begin{array}{l}\text { Headteachers: } \\
\text { Frequency }\end{array}$ \\
\hline Yes & $14(17.28 \%)$ & $4(23.53 \%)$ \\
\hline No & $17(20.99 \%)$ & $2(11.76 \%)$ \\
\hline I am not sure & $50(61.73 \%)$ & $11(64.71 \%)$ \\
\hline Total & $81(100 \%)$ & $17(100 \%)$ \\
\hline
\end{tabular}

As can be observed from Table 15, 14 (17.28\%) of the class teachers responded Yes to indicate that a majority of parents and members in their school communities knew about the NALAP. Nonetheless, $17(20.99 \%)$ and $50(61.73 \%)$ of them chose $N o$ and $I$ am not sure, respectively in response to the same statement (see questions 11 and 17 of the class teacher and headteacher questionnaires in the appendixes). On the part of the headteachers, $4(23.53 \%)$ affirmed that a majority of the members in the communities where their schools are located were aware of the NALAP. On the obverse side, 2 (11.76\%) and $11(64.71 \%)$ responded by $N o$ and I am not sure respectively. To further verify the level of community awareness of the NALAP, 20 parents were purposively selected and interviewed on whether or not they knew about the NALAP. Only $3(15 \%)$ said they had heard about the NALAP whilst the remaining $17(85 \%)$ said they had no idea of any existing school language programme called the NALAP. Again, the issue of a poorly informed public can have negative consequences for the NALAP in the Nkwanta North. This is premised on the fact that parents and the general community play such an important role in children's literacy development and learning in general. Keeping parents/the public well informed on the NALAP could have offered the opportunity for their more positive participation and support for their children's learning under the NALAP. 


\section{Summary of findings}

Firstly, results of the study suggest that there is a problem of linguistic disaggregation between the approved Ghanaian language MOI for the school on one hand and the L1 of the pupils and the local community on the other hand. This is because while Twi serves as the approved Ghanaian language MOI (66[81.48\%] and 16[94.12\%] of responses indicating this) as revealed in table 7 , respondents still maintained that a majority of pupils have Likpakpaln as their L1 and also that the dominant Ghanaian language of the Nkwanta North area is Likpakpaln. Thus, from table 5, 76 (93.83\%) and $15(88.24 \%)$ of class teachers and headteachers, respectively said that Likpakpaln is the majority language in the linguistic environs of their schools. Similarly, $74(91.36 \%)$ and $13(76.47 \%)$ of the class teachers and the headteacher respondents, as can be seen in table 6, identify Likpakpaln to be the L1 of a majority of the pupils. Relatedly, it was also found that a majority of the lower primary class teachers $(37[45.68 \%])$ are mother-tongue speakers of Likpakpaln. Twi and Ewe ran neck and neck in this regard as the number of class teachers who spoke Twi as L1 is the same as the number that spoke Ewe as L1, that is, 13 (16.04\%) in each case. Given the preceding sociolinguistic dynamics uncovered by the study, one can say that the use of Twi as the Ghanaian language MOI in the Nkwanta North defeats the very purpose and tenets of the NALAP. As has been pointed out (Leherr, 2009; Hartwell, 2010), a central quest of the NALAP is to provide Ghanaian children education through their mother-tongue and also doing so using the dominant native language in the locality of the school. Additionally, the present situation where the majority of pupils in the Nkwanta North lose the opportunity of education in their own mother-tongue clearly contravenes the famous pedagogical aphorism that children learn best when taught in their L1 (Owu-Ewie, 2006; UNESCO, 1953, p. 6, etc.). Again, Cummins and Genzuk (1991) argue that the greater use of a child's L1 in education makes it possible for parents to participate in and support their children's learning. It is true that Twi has a kind of lingua franca status in the Nkwanta North as in many other parts of Ghana, but for the majority of children in the 
Nkwanta North, Twi is acquired as a second language (L2) only later in life. This naturally makes it difficult, if not impossible, for such children to follow classroom instruction in Twi. One may also presume that teachers who do not speak Twi as an L1 may still have an L2 proficiency in it. Nonetheless, any such presumption further raises the question of whether or not such teachers' L2 proficiency in Twi will be sufficient to make them effectively deliver lessons using Twi. Then again, one has to be mindful of the issue of cultural attitude and satisfaction in the teacher having to use another's mother-tongue to teach, instead of his or her own mother tongue. As has been argued, the desire to use and to preserve one's own mother-tongue is universal and emotive (Azasu, 2012, p. 4). This view is also in congruence with the UNESCO (1953, p. 5) position that many millions in the world are interested and concerned with how they can employ their own native tongue both in their education and in their daily lives.

Further, another important finding made by this survey has to do with the provision of refresher courses or continual inservice training on language teaching for teachers. It was found that a significant $50(61.73 \%)$ of the lower primary teachers never attended any workshop relevant to language teaching. Again, out of the $31(38.27 \%)$ who ever benefitted from such in-service training, it is intriguing to learn that $3(9.68 \%)$ ever had that opportunity over 8 years ago and $9(29.03 \%) 7-8$ years ago. This situation strongly suggests that the teachers' language/literacy teaching skills are not being updated to make them competent enough to give quality instruction to the learners at their (teachers') feet. If considered vis-à-vis the implementation stipulations and recommendations of the NALAP, one can unequivocally say that the Nkwanta North situation presents a paradox of the NALAP. As clearly articulated in Hartwell (2010), an integral part of the NALAP implementation agenda is the periodic rolling out of language-related training/ workshops for teachers.

On the issue of availability of the NALAP teacher guide and other NALAP related TLMs, only 2, representing $11.76 \%$ of the 
headteachers agreed with the view that their schools had enough of these materials. A clear majority of $9(52.92 \%)$ and $6(35.29 \%)$, respectively, disagreed and strongly disagreed with the view that their schools had enough of such materials. Even more worrying is the reality that most of the schools did not seem to have a copy of the NALAP programme document in itself. As per the responses of the headteachers $13(76.47 \%)$ of them indicated that there were no copies of the NALAP policy document for reference in their various schools. A circumstance of this nature where the basic NALAP materials are lacking in the schools certainly amounts to nothing else, but an impediment to the implementation and realisation of the educational intents of this otherwise promising educational language programme in the district.

Finally, the survey also discovered that the level of public or stakeholder awareness of the NALAP in the Nkwanta North District rates so low. Neither the responses of teachers nor those of parents affirmed that members of the public knew about the NALAP. The low level of awareness of the NALAP is to the extent that some of the teachers themselves do not even know about it. As many as 17 , representing $20.99 \%$ of the teachers bluntly said that they did not know about the NALAP in Ghana. Following the prevailing phenomenon, one is tempted to proceed with the claim that the social marketing/public support component of the NALAP is not being attended to or, at best, is only being poorly catered for at present. A situation such as this can hold dire ramifications for the overall success of the NALAP. As it is known, an educational language policy as any other policy cannot properly succeed without a reasonably informed and supportive relevant stakeholder base.

\section{Implications of study}

In broader terms, the implications arising out of this study, as by others (Ansah \& Agyeman, 2015; Owu-Ewie, 2017, p. 167, etc.) hold that the government of Ghana needs to consider widening the school language net so that many more of the Ghanaian indigenous languages can be accommodated under the NALAP dispensation. This further means a turn away from the proto-typical practice 
in Ghana where government(s) hand-pick only a few (so-called government sponsored languages) or rely on the already developed languages as the qualified linguistic media for formal education. Simons and Fennig (eds.) (2017) in Ethnologue: Languages of the world estimate that 81 languages exist in Ghana. In such a highly multilingual state, many linguistic groups are bound to suffer undue educational disadvantages, if many of the local mother-tongues are not allowed for use as MOI in the school system. Since the Ghanaian officialdom has hardly ever systematically sought to inquire into who speaks what where in the country (Dako \& Quarcoo, 2017, p. 22), it is absolutely necessary that stakeholders in the various local areas are well consulted to know which language will best suit which local area, in case of adding to the list of Ghanaian languages in education.

As regards the Nkwanta North specifically, findings of this survey appear to glaringly suggest that it will be educationally more beneficial to approve (or add Likpakpaln to NALAP approved Ghanaian languages) and to use Likpakpaln for teaching and learning purposes in schools within the area. This is partly affirmed in the data in Table 8 where respondents indicate that Likpakpaln will serve as the preferable Ghanaian language medium in schools in the Nkwanta North. Once adopted, Likpakpaln can be made to replace Twi or be used concurrently with Twi. For the preceding suggestion to be implemented successfully in the Nkwanta North, a viable possibility will be that the District Education Directorate (DED), in collaboration with the national institutions such as the GES and MoE, can identify from the locality native speakers who have the potential to train as resource persons on NALAP. The role of these trained personnel will, in turn, be the provision of NALAP-oriented training/refresher courses and the development of associated TLMs in Likpakpaln.

Again, with the anticipation that there will be building of local capacity for NALAP-based training, it might be appropriate that the DED be given the charge to hold NALAP workshops for lower primary teachers at the beginning of every academic year. 
This way, the teachers can keep pace with standard classroom practices that foster the educational goals of the NALAP. Also, a poorly informed NALAP stakeholder phenomenon in the Nkwanta North can be tackled by entrusting the DED with some more of the NALAP social marketing responsibility. With the requisite resource generation and allocation, the DED can, from time to time, organise community durbars and town hall sessions, rely on community media channels such as community radios as well as use ParentTeacher Association (PTA) fora to enlighten the local publics on the NALAP.

Additionally, the DED ought to be utterly critical of the mother tongue or the linguistic proficiencies of a teacher when assigning him/her to any of the classes within the lower primary. That way, there can be some hope of a cessation to the current rate of violation of the educational and linguistic human rights of the school child in the Nkwanta North.

\section{Conclusion}

This study is an investigative survey into the prevailing implementation challenges faced by the NALAP in the Nkwanta North District of the Volta Region, Ghana. Findings of the survey point to the fact that the NALAP is in a quagmire in this area. This is premised on the fact that the prevailing realities in the Nkwanta North run contrary to both the spirit and the letter of the NALAP as a school language programme. To improve upon this situation, a clarion call is made for a recalibration in the local implementation scheme as contained in the course of action stipulated under implications of study above (section 9). This is particularly important, given that the entire terrain of Ghana's educational system (from the basic level up to the tertiary level) is already grappling with deleterious effects of policy-related challenges (Asaah, 2009, p. 66). Although this study is situated in the Nkwanta North District, its findings are also likely to have implications for the implementation of the NALAP in other parts of Ghana that have characteristics similar to those of the Nkwanta North. 


\section{References}

Andoh-Kumi, K. (1997). Language education policies in Ghana. Accra: Crigle. Ansah, N. G. (2014). Re-examining the fluctuation in language-in-education policies in post-independence Ghana. Multilingual Education, 4(12). Retrieved from DOI https://link.springer.com/article/10.1186/s13616014-0012-3

Ansah, A. M., \& Agyeman, A. N. (2015). Ghana language in-education-policy: The survival of two South Guan minority dialects. Per Linguam, 33(1), 89-104.

Anyidoho, A., \& Anyidoho, A. N. (2009). Political considerations in the choice of medium of instruction. Institute of African Studies Research Review Supplement, 19, 9-34.

Asaah, A. H. (2009). Adding value to the lecture in Ghanaian tertiary education institutions Institute of African Studies Research Review Supplement, $19,65-88$.

Awedoba, K. A. (2009). Attitudes towards instruction in the local language: A case study of the perspectives of the 'small' stakeholder. Institute of African Studies Research Review Supplement, 19, 35-64.

Azasu, K. (2012). The issue of a Ghanaian national language: A necessity but a dilemma. Gumaga: International Journal of language and Literature, $3,1-22$.

Baker, C. (2001). Foundations of bilingual education and bilingualism ( $3^{\text {rd }} \mathrm{ed}$.). Clevon, UK: Multilingual Matters.

Bamgbose, A. (2000). Language and exclusion: The consequences of language policies in Africa. Münster: LIT Verlag.

Bisilki, K. A. (2017). A sociolinguistic analysis of kinship terms in Likpakpaln (Konkomba). Ghana Journal of Linguistics, 6(3), 33-58.

Cummins, J., \& Genzuk, M. (1991). Analysis of final report longitudinal study of structured English immersion strategy, early exit and late exit transitional bilingual education programs for language-minority children. California Association for Bilingual Education Newsletter, 13.

Cummins, J. (2000). Language, power, and pedagogy: Bilingual children in the crossfire. Clevon: Multilingual Matters

Dako, K., \& Quarcoo, A. M. (2017). Attitudes towards English in Ghana. Legon Journal of the Humanities, 28(1), 20-30.

Das, A. K. (2002). Language conflict in India. Journal of Philology, 2(10), 20-23.

Galloway, J. P. (1992). Teaching education computing with analogies: A strategy to enhance concept development. Journal of Research on Computing in Education, 24(3), 499-512.

Ghana Education Service, Nkwanta North. (2017). Nkwanta North annual district performance report 2017/2018 (unpublished). Kpassa: Ghana Education Service.

Ghana Statistical Service. (2012). 2010 population and housing census. Accra: Ghana Statistical Service. 
Ghana Statistical Service. (2014). 2010 Population and housing census: District analytical report - Nkwanta North District. Accra: Ghana Statistical Service.

Hartwell, A. (2010). National Literacy Acceleration Program (NALAP): Implementation study. Accra: Education Development Centre/ EQUALL.

Improving Education Quality. (2000). Implementation of the school language policy in Ghana: Interim report. Washington, DC: American Institutes for Research.

Leherr, K. (2009). National Literacy Acceleration Program (NALAP): Baseline assessment. Accra: Education Development Centre/USAID.

Maalim, H. A. (2015). The replacement of Swahili medium of instruction by English from grade five in Zanzibar: From complementary to contradictory. Nordic Journal of African Studies, 24(1), 45-62.

Močinić, A. (2011). Bilingual education. Metodički Obzori, 6(13), 175-182.

Mose, P. N. (2017). Language-in-education policy in Kenya: Intention, interpretation, implementation. Nordic Journal of African Studies, 26(3), 215-230.

Nkwanta North District Assembly. (2015). The composite budget of the Nkwanta North District Assembly for the 2015 fiscal year.

Owu-Ewie, C. (2006). Language policy of education in Ghana: A critical look at the English-only language policy of education. In J. Mugane et al. (Eds.), Selected Proceedings of the 35th Annual Conference on African Linguistics (pp. 76-85). Somerville, MA: Cascadilla Proceedings Project

Owu-Ewie, C. (2017). Language, education and linguistic human rights in Ghana. Legon Journal of the Humanities, 28(2), 151-172.

Schilling, N. (2013). Surveys and interviews. In R. J. Podesva \& D. Sharma (Eds.), Research methods in linguistics (pp. 96-115). New York: Cambridge University Press

Simons, G. F., \& Fennig. D. C. (Eds.) (2017), Ethnologue: Languages of the world (20th ed.). Dallas: SIL International. Retrieved from http:// www.ethnologue.com

Skutnabb-Kangas, T., \& Phillipson, R. (1994). Linguistic human rights: Overcoming linguistic discrimination. Contributions to the Sociology of Language, 67. Berlin: Mouton de Gruyter

Spolsky, B. (2009). Language management. Cambridge: Cambridge University Press

UNESCO. (1953). Monographs on fundamental education-VIII: The use of vernacular languages in education. Paris: UNESCO

UNHCR. (2010). Declaration on the rights of persons belonging to national or ethnic, religious and linguistic minorities. Geneva: UNHCR 